\title{
The Cerebrospinal Fluid-Contacting Neuron: A Peculiar Cell Type of the Central Nervous System. Immunocytochemical
} Aspects*

\author{
Ingeborg Vigh-TeichmanN and Béla Vigh \\ Neuroendocrine Laboratory of the Hungarian Academy of Sciences-Semmelweis Medical University Joint Research Organization \\ at the 2nd Department of Anatomy, Semmelweis Medical University, Budapest, Hungary
}

\begin{abstract}
Summary. Cerebrospinal fluid (CSF)-contacting neurons are located periventricularly or inside the brain ventricles; they contact the CSF via their dendrites, perikarya or axons. Most of these neurons form ciliated dendrite terminals in the internal CSF as do retinal and pineal photoreceptors in the optic ventricle and pineal recess. The peculiar localization, polarization and synaptic connections of the CSF-contacting neuronal elements suggest receptor and integrative functions.

The present review pays special attention to vitamin A (retinoids) immunoreactivity in CSF-contacting neurons as compared with that present in retinal and pineal photoreceptor cells, common neurons, glial and adenohypophysial cells. The immunoreactivity of the darkadapted photoreceptor outer segments was strong, but decreased after illumination, suggesting the functioning of vitamin $A$ as the chromophore of the retinal and pineal photopigments. Retinoid immunoreaction was also found in the endoplasmic reticulum, nuclei, nucleoli and mitochondria of the cell types studied. This cytological localization suggests that vitamin A compounds may be involved in the function of these organelles.
\end{abstract}

The CSF-contacting neurons contain varying amounts of bioactive materials. The intracellular distribution of immunoreactive serotonin (5-HT), substance $P$ (SP) and gamma-aminobutyric acid (GABA) is compared with that of immunoreactive vitamin A. Immunogold labeling for SP was demonstrated in dense-core vesicles of preoptic neurons; 5-HT marking was found on the dense-core vesicles of subependymal CSF-contacting neurons of the paraventricular organ, while GABA immunoreaction was localized in the cytoplasm of distal infundibular CSF-contacting neurons.

The CSF-contacting neurons are considered to synthesize and release their bioactive substances at transmitter synapses, and/or at neurohormonal terminals into the external $C S F$ in accord with information received by their dendrites from the internal CSF and by afferent fiber connections from various brain areas.

The expression "CSF-contacting neuron" (VIGH et al., 1969) was introduced for designating nerve cells that penetrate the CSF-brain barrier by their dendrites, perikarya or axons (Figs. 1, 16). All CSF-contacting neuronal structures are considered to comprise the CSF-contacting neuronal system (VIGH et al., 1969; VIGH-TEICHMANN and VIGH, 1983) believed to have enteroceptor functions (VIGH and VIGH-TEICHMANN, 1987).

CSF-contacting neurons are located in the periventricular grey and/or inside the CSF cavities (Fig. 1) of all vertebrate classes (for review, see VIGH and Vigh-TEICHMANN 1971，1973，1988a; Vigh-TeICHMANN and VIGH, 1974, 1979, 1983, 1985). Such neurons occur first of all in the diencephalon and medullospinal area. In addition, the photoreceptor cells of the retina and the pinealocytes are considered CSF-contacting neuronal elements because of their localization around the optic ventricle (the photoreceptor space) and pineal recess, respectively, their development from the diencephalic primordium and their cytological polarization into a CSF-contacting dendritic and an axonic pole. Moreover, the retina and pineal organ contain a varying number of "true" CSF-contacting neurons such as those retinal bipolars forming Landolt's clubs (VIGH et al., 1983b) and like some of the intrinsic pineal neurons (Figs. 2-4). The latter were first demonstrated in Chimaera monstrosa by electron

*This investigation was supported by the Hungarian OTKA grant Nr. 1619. 
microscopy (VIGH-TEICHMANN and VIGH, 1987; VIGH and Vigh-TeichmanN, 1988a, b). These retinal and pineal CSF-contacting nerve cells receive ribboncontaining axon terminals from the photoreceptor cells and serve as secondary neurons in the light perceiving pathway. Their function probably depends on the information received by their $9 \times 2+0$ cilia from the CSF in the photoreceptor space and pineal lumen.

The periventricular CSF-contacting neurons numerous in submammalian species - are characterized by their dendrites extending into the ventricular cavity and central canal (Fig. 1) and by their basic process giving rise to the axon passing into the neuropil and/or terminating in neurohemal areas. In the CSF, the dendrites of the epi- and hypothalamic CSF-contacting neurons form bulb-like terminals bearing a sensory $9 \times 2+0$ cilium (Fig. 1)

The cytological appearance of the dendrite terminals refutes the earlier concept (lit. see LEONHARDT, 1980) that they may be detached by macroapocrine secretion into the CSF. Although cytological evidence is lacking, the exocytotic secretion of bioactive materials contained in the dense-core vesicles of the dendrites cannot be excluded in view of recent data on a release of neurotransmitters from dendrites (GEFFEN et al., 1976). Here, we would like to emphasize that the $9 \times 2+0$ cilia of the diencephalic CSFcontacting dendrite terminals resemble those of developing photoreceptors and simple chemoreceptors.

In contrast, most of the medullo-spinal CSFcontacting neurons display numerous stereocilia together with a $9 \times 2+2$ kinocilium, a pattern usually found in mechanoreceptors and some chemoreceptors. The axons of the spinal CSF-contacting neurons form neurohormonal terminals on the basal lamina of the spinal cord (VIGH et al., 1974, 1977, 1979). Their bioactive materials thus released may act directly on the subarachnoid vessels and/or act indirectly on target organs via the external CSF and blood. The regulation of the vessels is supposed to influence the homeostasis of the nervous tissue and CSF.

The perikarya of intraventricular neurons which are supported by glial cells (VIGH-TEICHMANN and VIGH, 1974, 1983; Vigh-TEICHMANN et al., 1980a, 1981), lie in the ventricular cavity, exhibit a sensory $9 \times 2+0$ cilium and a bipolar, pseudounipolar or multipolar (isodendritic or pyramidal) shape. Therefore, by their cytology and polarization, the periventricular and intraventricular CSF-contacting neurons are supposed to function as sensors of cer- tain parameters of the CSF (hormonereceptors, chemoreceptors, light receptors, thermoreceptors, mechanoreceptors). As we have already suggested (VIGH-TeichmanN and VIGH, 1983, 1985; VIGH and VIGH-TEICHMANN, 1988a) some of the CSF-contacting neurons also serve integrative functions.

Thus, the CSF-contacting neurons could represent the morphological basis for some of the mechano-, thermo-, chemo- and so-called "deep encephalic" photoreceptors believed to occur in the walls of the brain ventricles and central canal by experimental studies (VON FRISCH, 1911; SCHARRER, 1928; VERNEY, 1947; JEWELL and VERNEY, 1957; ANDERSSON, 1972; HELLON, 1972; RODRIGUEZ et al., 1974; KoRF et al., 1982; GriLlner et al., 1982; INENAGA et al., 1987). Electrophysiological results obtained from the frog paraventricular organ contradict an extraretinal photoreceptive function of the organ (GEORGE and MEISSL, 1987). In the spinal cord, a mechanoreceptor was supposed to be present in the marginal nucleus whose neurons project villus-like processes into the intercellular space (GRILLNER et al., 1982, 1984; SCHROEDER, 1986) that are similar to those of mechanoreceptors and spinal CSF-contacting neurons. All these morphological and experimental data point to the presence of a system of enteroceptors inside the central nervous system (VIGH and VIGHTEICHMANN, 1987).

Several kinds of CSF-contacting axons running on the apical surface of the ependyma of the brain ventricles and central canal (lit. see LEONHARDT, 1980; VIGH-TEICHMANN and VIGH, 1983; VIGH et al., $1979,1983 a$ ) have been described as to the content and size of their synaptic and/or dense-core vesicles. One type of nerve fiber was found to contain serotonin by autoradiography, cytochemistry and immunoreaction (RICHARDS and TRANZER, 1974; TrAmU et al., 1983; MATSUURA et al., 1985) and to originate from the raphe nuclei (AGHAJANIAN and GALLAGER, 1975). Thus, some of the raphe neurons are obviously CSFcontacting neurons through their axons running intraventricularly (Fig. 16).

The CSF-contacting axons synapse with the apical surface of the ependyma, with the ciliated dendrites of periventricular CSF-contacting neurons as well as with the perikarya and dendrites of intraventricular nerve cells (Figs. 1, 16) (lit. see VIGH-TEICHMANN et al., 1980a, 1981). They also terminate on myeloid bodiescontaining pineal ependymal cells (VIGH-TEICHMANN et al., 1973). Thus, the axons contribute to the formation of a supraependymal neuropil that probably ensures the appropriate coordination of the innervated structures. 


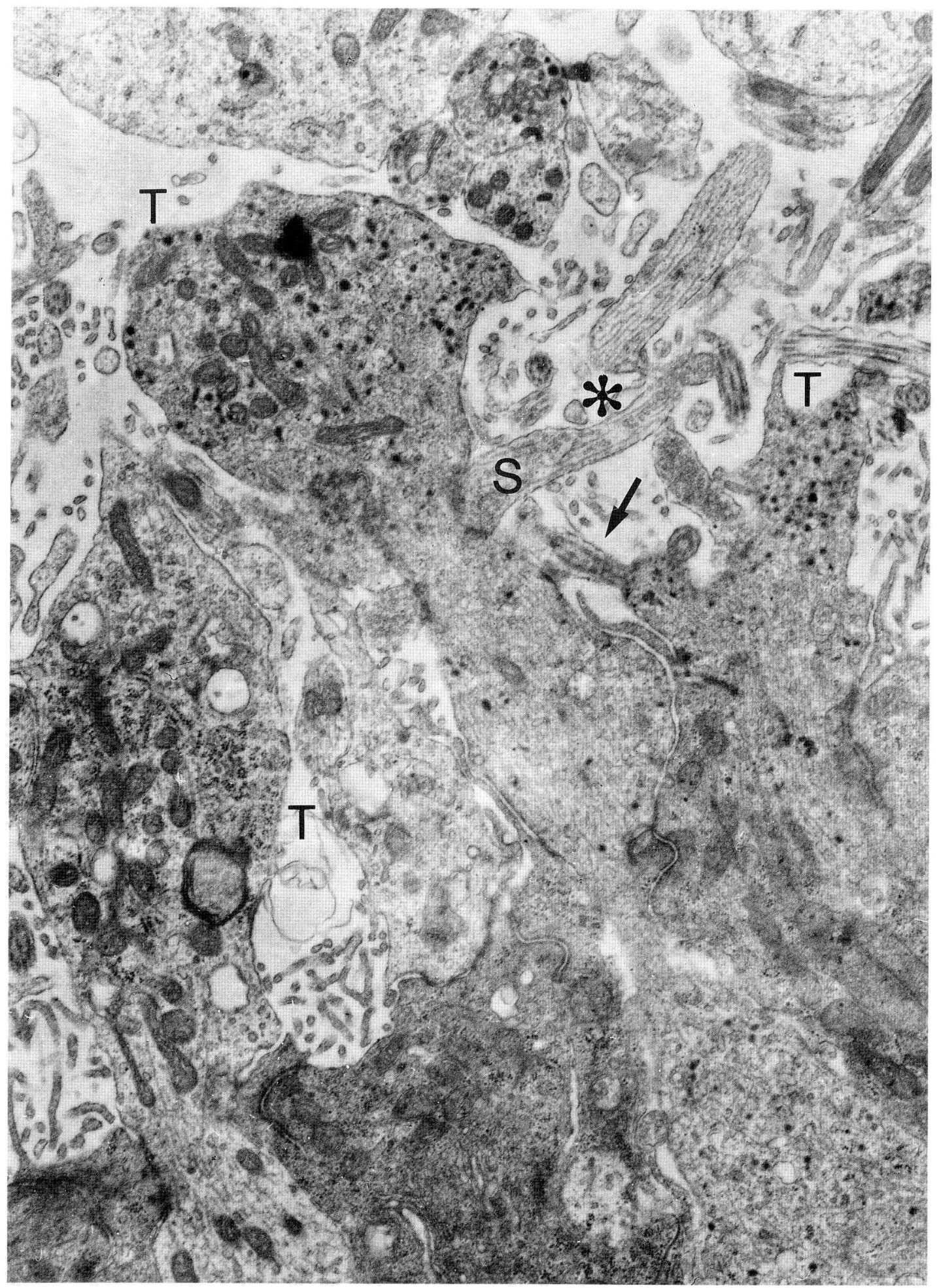

Fig. 1. Electron-dense and electron-lucent CSF-contacting dendrite terminals $(T)$ in the paraventricular organ of Emys orbicularis. At arrow arising cilium, asterisk intraventricular axon forming synapse $(S)$ with neck portion of dendrite ending containing granulated vesicles. $\times 11,000$ 
With regard to bioactive substances - peptides, amino acids and monoamines - in CSF-contacting neurons and their processes, numerous data have been published (for earlier data, see VIGH-TEICH. MANN and VIGH, 1983, 1985), especially with regard to the distribution of peptides in periventricular CSFcontacting neurons. In such cells of the spinal cord, enkephalin, urotensin II, somatostatin, vasoactive intestinal polypeptide (VIP) as well as serotonin and GABA were found. In the hypothalamus, immunoreactivity for more than twenty bioactive materials was reported, including neurohypophysial hormones, hypophyseotrop releasing factors, further gut peptides, substance P (YUI, 1983) and monoamines. The alloted space for our review does not allow the citing of all data, for which we here restrict ourselves to those of the paraventricular organ and selected substances.

In the submammalian paraventricular organ (PVO) in which the CSF-contacting neurons were first described by acetylcholinesterase reaction, induced monoamine fluorescence and electron microscopy (earlier lit., see VIGH-TEICHMANN and VIGH, 1974, 1983), immunocytochemical studies demonstrated enkephalin (DOERR-SCHOTT et al., 1981; NAIK et al., 1981) and choline acetyltransferase (EKSTRÖM, 1987), an enzyme catalyzing the last step in acetylcholine synthesis. Further, the presence of serotonin (Yo. SHIDA et al., 1982; SANO et al., 1983; EKSTRÖM et al., 1985; FASOLO et al., 1986; a.o.) and dopamine (GEF. FARD et al., 1982) was confirmed. Dopamine was also indirectly detected by tyrosine hydroxylase immunoreaction (NAGATSU et al., 1984; FRANZONI et al., 1987).

All these immunohistochemical data show that by their bioactive materials - the CSF-contacting neuronal system is composed of different populations of neurons. As to which of the numerous substances occur in separate cells or concomittantly is a problem for future studies. Research performed to localize, e. g., tyrosin hydroxylase, serotonin and GABA by immunoelectron microscopy, has used the preembedding peroxidase antiperoxidase method (NAGATSU et al., 1984; FRANZONI et al., 1987; DALE et al., 1987; KADURI et al., 1987; MAGOUL et al., 1987). Data on postembedding immunoelectron microscopy employing the immunogold technique - affording more precise IgG-gold marking of antigenic sites - are so far lacking in regard to CSF-contacting neurons.

Earlier, we demonstrated the receptor protein opsin of photopigments in the pineal organ by light and electron microscopic immunocytochemistry (Vigh-Teichmann et al., 1980b, 1986; Vigh-TeichMANN and VIGH, 1986; VIGH and VIGH-TEICHMANN,
1981, 1986), a discovery strengthening the view of its light percepting capacity. Searching for "deep encephalic photoreceptors" we found no (rhod) opsin immunoreaction in the hypothalamic and spinal CSFcontacting neurons studied (VIGH-TEICHMANN et al., 1980b; VIGH et al., 1983b). Similar results were obtained by FOSTER et al. (1987). Since cone photoreceptors are likewise opsin-negative, this result does not exclude the possibility that some CSF-contacting neurons resemble cones. SILVER et al. (1988) found opsin immunoreactivity in VIP-positive CSF. contacting neurons of the septum and infundibulum of birds, but the crossreacting compound did not correspond to opsin according to the saturation and immunoblot studies (SILVER et al., 1988).

In connection with our opsin studies, we have recently looked for vitamin $\mathrm{A}$, the chromophore component of photopigments in retina and pineal organ of various vertebrates (VIGH et al., 1987; VIGHTEICHMANN et al., 1987, 1988, 1989). Here, we summarize our results on the distribution of immunoreactive vitamin A in CSF-contacting elements in comparison with pineal and retinal photoreceptors as well as glial and adenohypophysial cells. Finally, we would like to report our first data on the finestructural localization of SP, 5-HT and GABA - candidates for transmitters and/or hormones - in CSF-contacting neurons of the preoptic area, paraventricular organ, infundibular lobe, retina and pineal organ, respectively, by the electron microscopic immunogold technique.

\section{MATERIALS AND METHODS}

The following species were used: Myxine glutinosa, larval and adult Lampetra planeri Bloch, Triturus vulgaris, Bombina variegata, Pelobates fuscus, Rana esculenta, R. catesbeiana, Emys orbicularis, Peudemys scripta elegans, Columba livia and cock, further Erinaceus roumanicus, Myotis blythi oxygnathus, rabbit and laboratory rat. The animals were fixed by immersion in $4 \%$ paraformaldehyde (PF), $4 \%$ PF- 0.2 to $2 \%$ glutaraldehyde or $3 \%$ to $5 \%$ glutaraldehyde solved in phosphate buffer, at $\mathrm{pH} 6.5$ to 7.4. For vitamin $\mathrm{A}$ immunoreaction, the material was usually dark-adapted prior to fixation under dim red or yellow light. After washing in buffer overnight, the diencephalon including the eyes, pineal complex, hypophysis and pieces of spinal cord were cut frozen or dehydrated in $50 \%$ and $70 \%$ ethanol and embedded in LR White (Polysciences, St. Goar, FRG). In addition, pieces of tissues were postfixed in osmic acid and embedded in LR White or Araldite (Fluka, 




Figs. 2-4. Details of CSF-contacting neurons in the pineal organ of Chimaera monstrosa. Fig. 2. The pineal secondary neuron $(S)$ contacts the pineal lumen by a dendrite (arrow). E ependyma. $\times 15,000$. Fig. 3 . The CSF-contacting dendrite terminal of the secondary neuron contains numerous mitochondria $(M)$. $E$ ependyma, $L$ pineal lumen. $\times 31,000$. Fig. 4 . Axosomatic synapse (arrow) formed on the perikaryon of a CSF-contacting neuron by synaptic ribbon-containing axon terminal of pineal photoreceptor cell. $V$ synaptic vesicles. $\times 46,000$ 



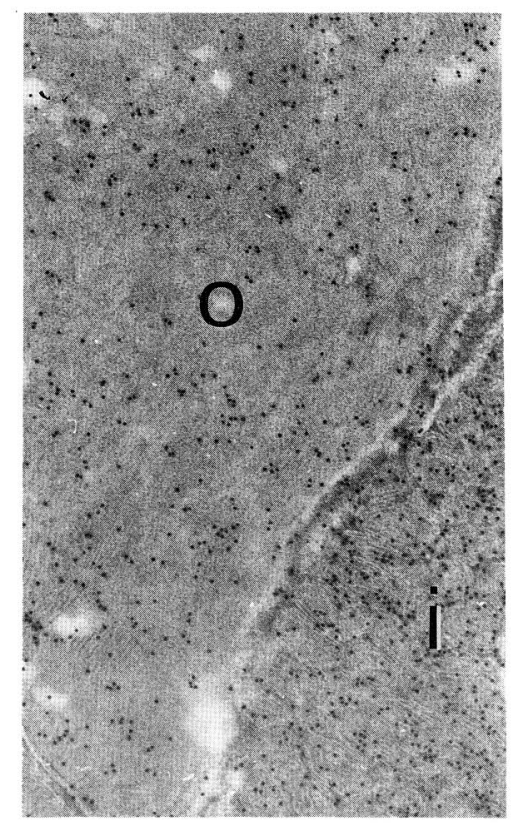

8

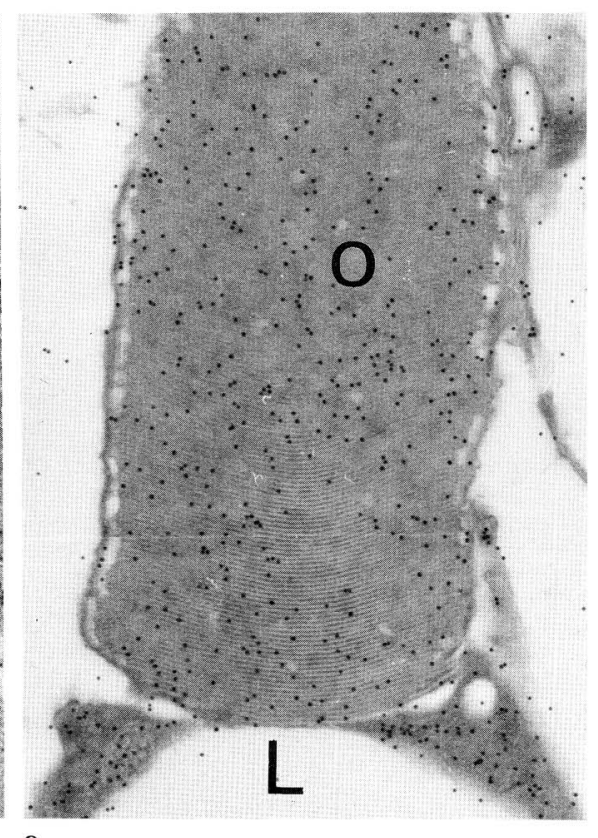

9

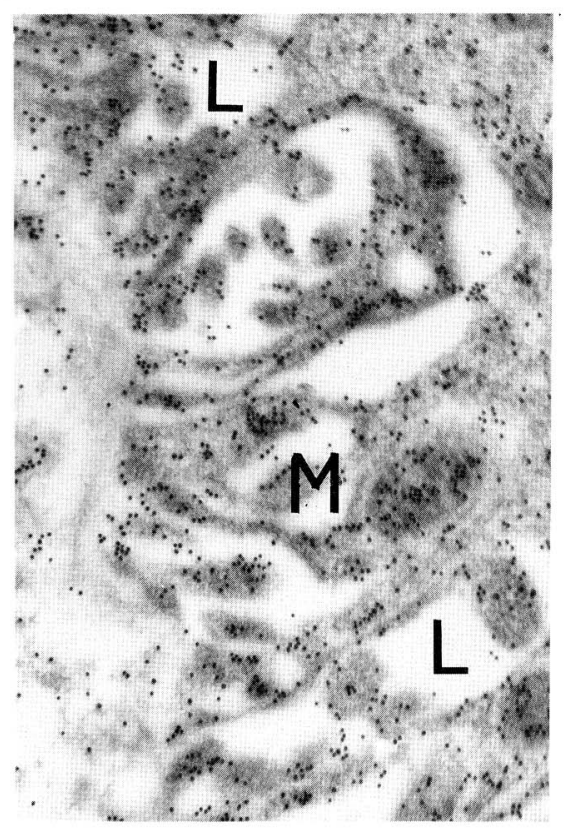

10

Figs. 5-10. Vitamin A immunogold reaction in the pineal organ of Rana esculenta (Figs. 5, 6) and retina (Figs. 7-10). Fig. 5. Gold labeling (10 nm black dots) of rod-type outer segment $(o)$ and endoplasmic reticulum (asterisk) of inner segment. $\times 37,000$. Inset. Vitamin A-immunoreactive photoreceptor membranes at higher magnification. $\times 76,000$. Fig. 6. Few gold particles are found on this outer segment $(o)$ fixed under dim yellow light. At arrow connecting cilium. $\times 60,000$. Fig. 7. Vitamin A immunoreaction in the outer $(0)$ and inner $(i)$ segments of rods and pigment epithelium $(p)$ of rat. PAP reaction. $\times 1,100$. Fig. 8. Vitamin A IgG-gold (10 nm 
Buchs, Switzerland).

Cryostat sections $(12 \mu \mathrm{m})$ or ultrathin sections collected on $\mathrm{Ni}$ grids were used for the immunocytochemical reactions. Polyclonal rabbit anti-serotonin and anti-substance P (L. JEnNEs, Dayton, USA; Im- muno Tech. Inc., Chapel Hill, USA), anti-GABA (H. PeTter, Leipzig, GDR), and anti-retinoic acid (CONRAD and WIRTZ, 1973) were used in combination with the peroxidase antiperoxidase (PAP) reaction at the light microscopic level, or with the immuno-

11
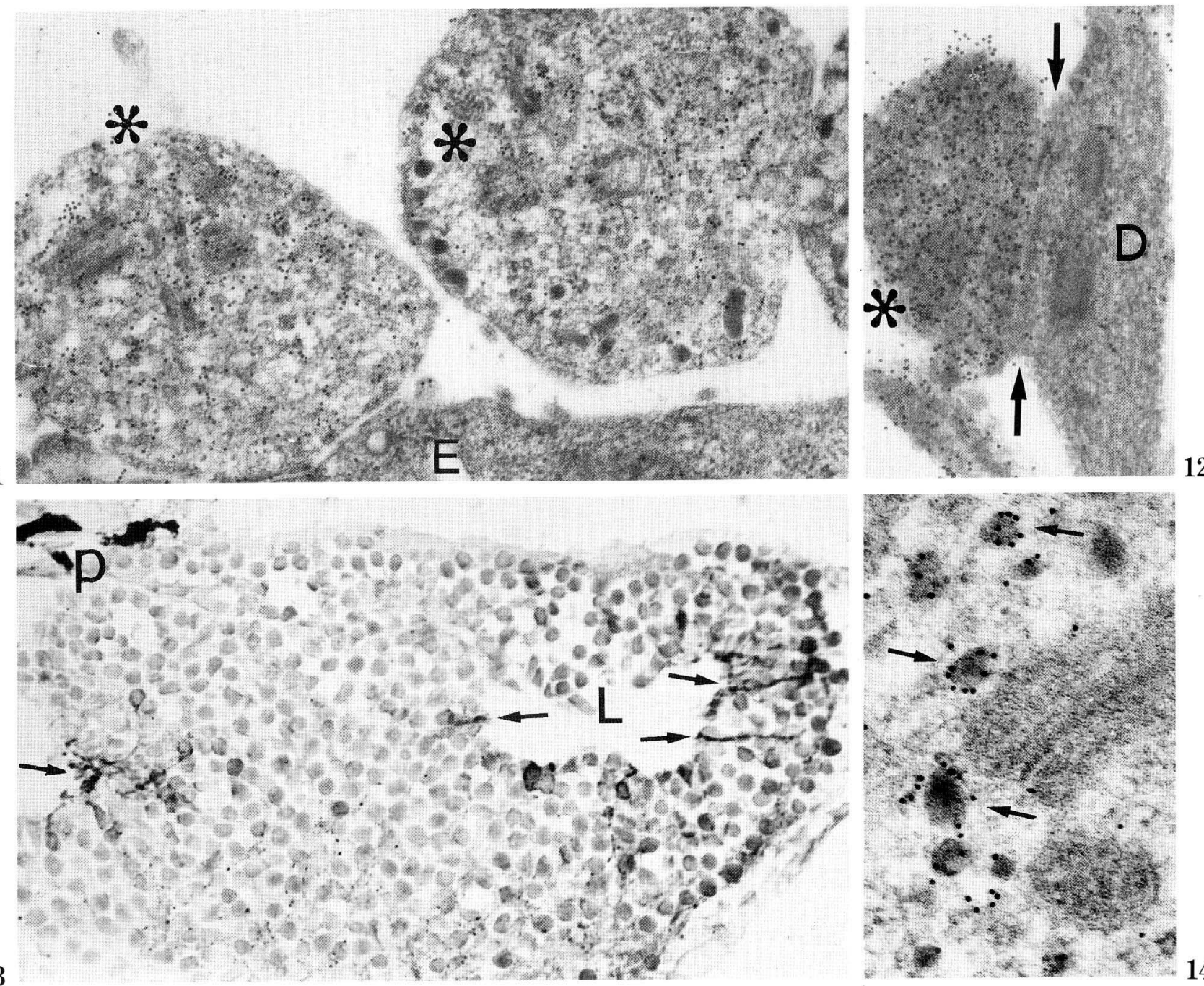

Figs. 11-14. GABA IgG-gold labeling in the infundibular lobe of Pelobates fuscus (Figs. 11, 12) and immunoreactive serotonin in the paraventricular organ of the newt (Fig. 13) and pigeon (Fig. 14). Fig. 11. Immunoreactive CSF-contacting dendrites (asterisks) of distal CSF-contacting neurons. $E$ unlabeled ependyma. $\times 24,000$. Fig. 12. GABA IgG-gold labeled axon terminal (asterisk) forms synapse (arrow) on immunonegative dendrite (D). $\times 42,000$. Fig. 13. Serotonin immunoreactive CSF-contecting neurons (arrows) of PVO. L. lateral recess of infundibular lobe, $P$ pigmented cells. PAP reaction. $\times 200$. Fig. 14. Serotonin IgG-gold labeling of dense-core vesicles (arrows) and their surrounding. $\times 56,000$

(from p. 200)

black dots) labeling in rod outer $(o)$ and inner $(i)$ segment. Pelobates fuscus. $\times 27,000$. Fig. 9. Vitamin Aimmunoreactive (15 nm gold particles) cone outer $(o)$ segment of cock retina. $L$ vacuole of lipid droplet. $\times 27,000$. Fig. 10. Strong gold labeling in the basal labyrinthic portion $(L)$ of bat pigment epithelial cell. $M$ mitochondrium. $\times 34,000$ 
globulin-gold (IgG-gold) method for electron microscopy (for details, see VIGH-TEICHMANN et al., 1988, 1989). The vitamin A antiserum crossreacts with retinol and retinal (WIRTZ and WESTFALL, 1981). The primary antisera could be saturated with an appropriate amount of antigen. Control sections incubated with IgG-gold (Janssen Pharmaceuticals, Beerse, Belgium) alone were immunonegative. In designating the immunoreactive elements as specifically "antigencontaining", however, we are mindful of the possibility of an immunologic crossreaction with yet unknown tissue compounds.

\section{RESULTS}

\section{Vitamin A immunoreaction}

A clear-cut immunoreaction was found in the outer and inner segments of the photoreceptor cells of the retina of Rana esculenta, Pelobates fuscus, the cock, Myotis blythi oxygnathus and rat, as well as in those of the pineal organ of the lamprey and frog fixed under dim red light (Figs. 5-9). Both rod and cone photoreceptors were immunoreactive. In dark-adapted material fixed under dim yellow light, the connecting cilia and inner segments of certain photoreceptor cells displayed a more intense vitamin A IgG-gold labeling than the corresponding segment, a phenomenon already described for photoreceptor cilia in the retina (VIGH-TeichmanN et al., 1988) and presently under study with regard to the different types of photoreceptors of the pineal complex (VIGH and Vigh-Teichmann, 1986, 1988a). The intensity of the immunoreaction was considerably decreased in the outer and inner segments of the retina and pineal when the animal was adapted to room light prior to fixation.

In addition, gold particles labeled to varying degrees the mitochondria and endoplasmic reticulum of the inner segments (Figs. 5, 8) and perikarya, in addition to the euchromatin of nuclei and the electron-dense fibrillar component of nucleoli of retinal and pineal photoreceptors, neurons, glial and adenohypophysial cells. Granulated and synaptic vesicles present, e.g., in the neurohormonal axon terminals of pigeon pinealocytes (see VIGH and VIGHTeichmann, 1989) were unmarked. There was no considerable difference between the moderate IgGgold labeling of the CSF-contacting neurons and non-CSF-contacting hypothalamic neuronal structures studied. In the pigment epithelium and pineal

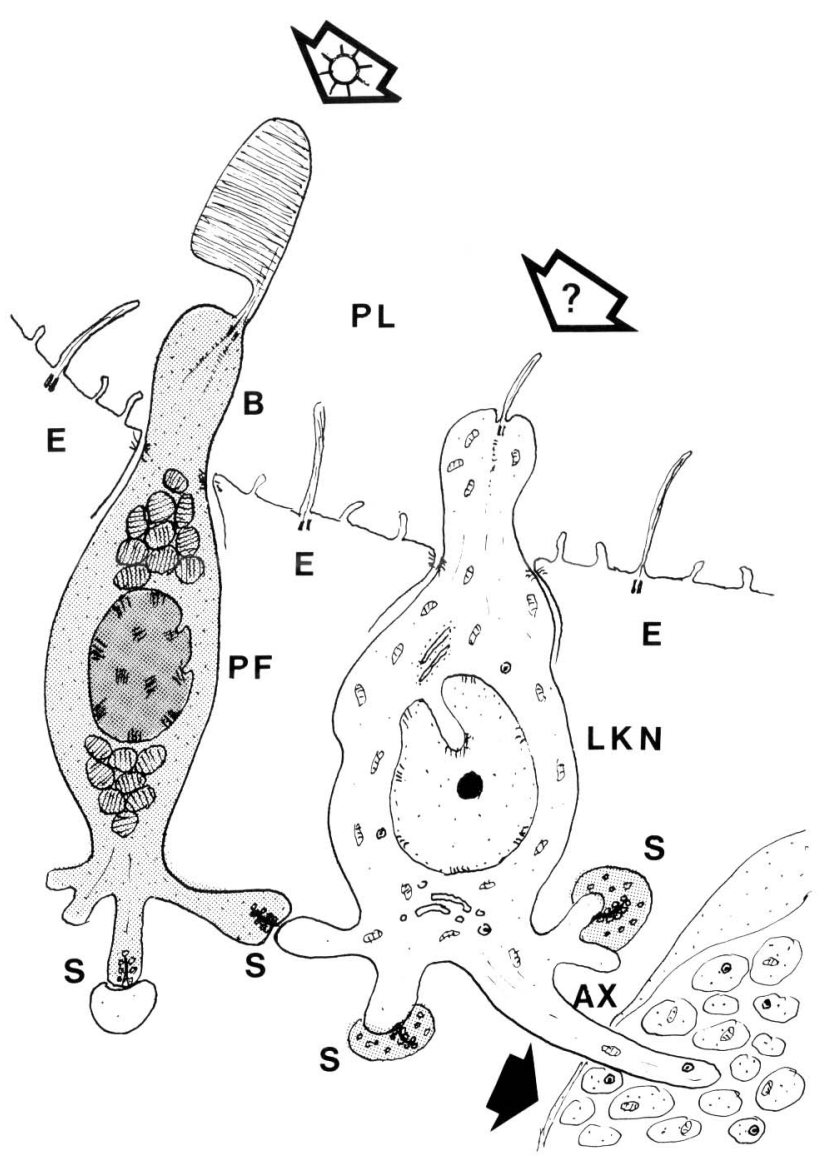

Fig. 15. Scheme of the pineal CSF-contacting neuron $(L K N)$, the secondary neuron of the pineal light perceiving pathway. $A X$ axon entering the pineal tract (black arrow), $B$ inner segment of photoreceptor cell $(P F)$ dis playing outer segment, $P L$ pineal lumen, $S$ synapses formed by ribbon-containing axons of photoreceptor cells. White arrows represent afferentation.

ependyma, phagocytozed outer segments, myeloid bodies and perivascular labyrinths, further glial endfeet exhibited immunoreactions of varying intensities (Fig. 10).

\section{Substance P, GABA and serotonin immunoreac- tivities}

Pubstance $P$ IgG-gold binding was observed in the dense-core vesicles of CSF-contacting dendrite terminals of hypendymal parvocellular preoptic neurons of Bombina variegata. In contrast, the GABA immunoreaction was localized diffusely in the cytoplasm of distal CSF-contacting neurons of the infundibular 


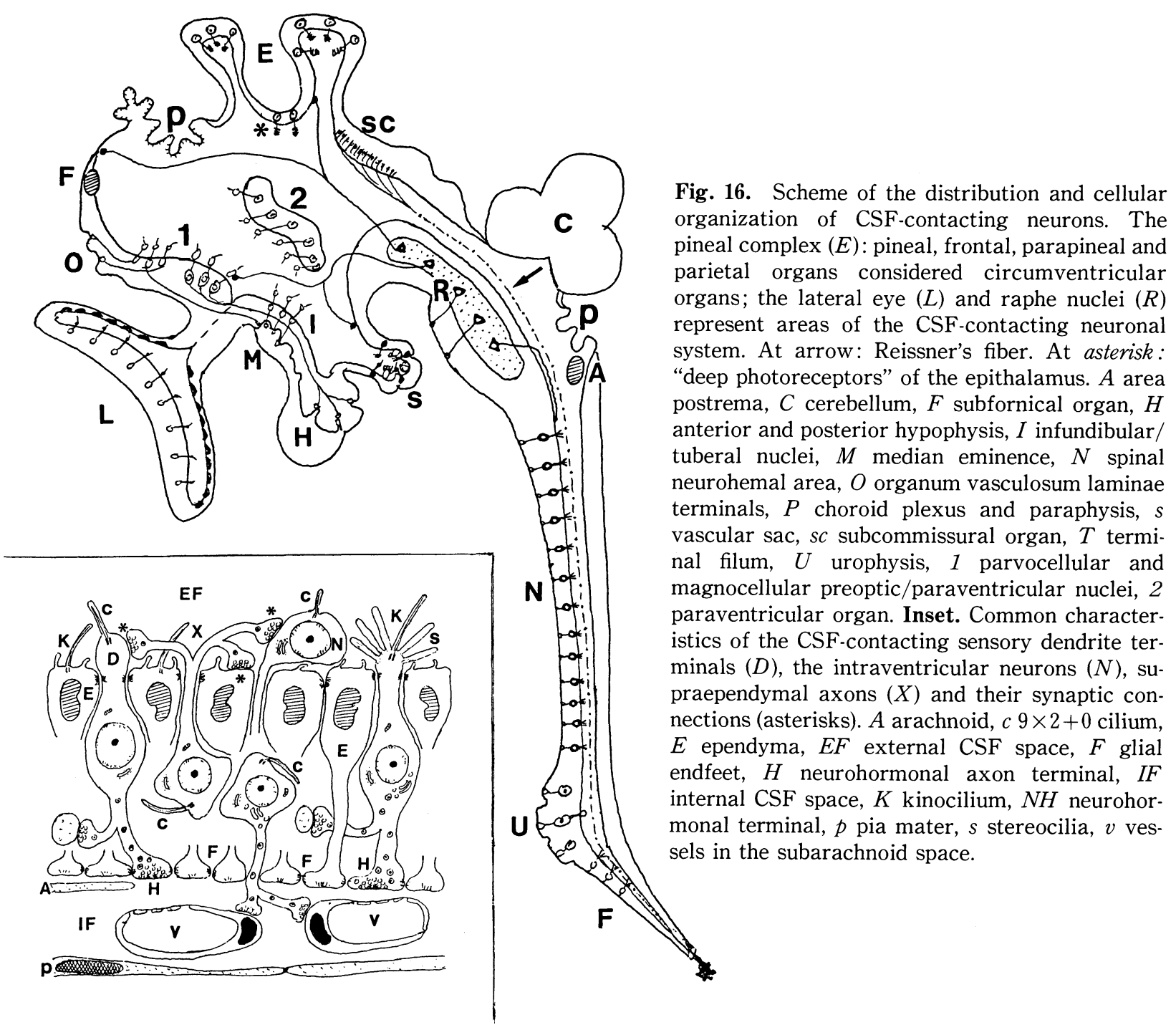

lobe of Pelobates fuscus, their axons and CSF. contacting dendrites (Fig. 11), while the proximal CSF-contacting neurons were unlabeled. There were axo-dendritic synapses between GABA immunoreactive axon terminals and immunonegative dendrites (Fig. 12). Glial processes and the ependyma were unstained. Further, GABA immunoreaction was not only found in nerve cells of the bipolar layer of the retina - as already known from previous light microscopic studies (AGARDH et al., 1987) - but also in some of the intrinsic neurons of the frog pineal organ at the electron microscopic level. Serotonin immunoreactivity was detected in the hypendymal
CSF-contacting neurons of the paraventricular organ of Triturus vulgaris (Fig. 13), the hagfish and pigeon.

The IgG-gold particles marked serotoninimmunoreactive sites to the dense-core vesicles of these cells (Fig. 14). Some gold particles were also visible surrounding the vesicles. A second kind of hypendymal CSF-contacting neuron of the pigeon paraventricular organ contained numerous unlabeled granulated vesicles, probably the dopaminecontaining ones. These results are in agreement with earlier authors who demonstrated monoamines in separate neurons by induced monoamine fluorescence (earlier lit. see, VIGH-TEICHMANN annd VIGH, 1974). 


\section{DISCUSSION}

Although CSF-contacting neurons and the retinal and pineal photoreceptor cells exhibit similar principles of construction, our results show that they differ from each other in certain respects. For example, in the pineal organ of Chimaera monstrosa, the CSFcontacting neurons receive ribbon-containing axon terminals from photoreceptor pinealocytes (Fig. 15). Thus, the CSF-contacting neurons of the pineal of this species are actually secondary neurons in the pineal light-perceiving pathway. From this point of view they behave like retinal Landolt's bipolar cells, which also receive synapses from photoreceptor cells and at the same time represent a retinal CSF-contacting neuron type. At present, we cannot answer the question whether the receptor dendrite terminal of the pineal and retinal CSF-contacting neurons might perceive some information about the state (ionic composition?) of the fluid of the pineal recess and retinal photoreceptor space, the latter being the remnant of the embryonic optic ventricle, a diverticle of the third brain ventricle. Nevertheless, the presence of the CSF-contacting dendrite terminals and their sensory cilia suggests a sensory capacity.

Our immunocytochemical studies revealed vitamin A compounds in two main locations. Strong vitamin A IgG-gold labeling was found in the outer segments of the retinal and pineal photoreceptor cells. Obviously, this vitamin A represents the chromophore of the photopigments, since the intensity of the immunoreaction decreased upon illumination prior to fixation, most certainly due to known conformational changes caused in the photopigments by light (lit., see Vigh-TEICHMANN et al., 1988). An additional weak retinoid immunoreactivity - probably of retinoic acid and retinol - occurred in all cell types studied, a finding in accord with biochemical data on the presence of retinoid binding proteins in various cell types (ChYTIL and ONG, 1987). Cytologically, the retinoid immunoreaction marked to various degrees the euchromatin of nuclei, compact nucleoli, endoplasmic reticulum and mitochondria of the neural and adenohypophysial tissues studied. This cytological localization suggests that retinoids may be involved in the functioning of cell organelles connected with ribonucleoprotein and/or protein synthesis (lit., see VIGHTEICHMANN et al., 1989).

The occurrence of immunoreactivity for substance $\mathrm{P}, \mathrm{GABA}$ and 5-HT was found in different types of CSF-contacting neurons, a result indicating the multiplicity of the latter. Probably, those studied use different transmitters/neurohormones for the transfer of information. The spinal CSF-contacting neurons were found to form neurohormonal terminals on the surface of the oblongate medulla and spinal cord (Vigh and Vigh-TeichmanN, 1973; VIGH et al., 1983a). Consequently, the materials produced in these cells may act as hormones via the external CSF on target organs (for review, see LARSON and BERN, 1987). The axons of hypothalamic and spinal CSFcontacting neurons also form common synapses suggesting a neural output of the perceived information (see Vigh-TEICHMANN and Vigh, 1979).

The question is still unanswered as to what kind of information is taken up by the ciliated intraventricular dendrite terminals of the CSF-contacting neurons. Those studied by us are obviously not rodlike photosensitive elements, as they are rhodopsinimmunonegative. With regard to the paraventricular organ, such a conclusion was also strengthened by electrophysiology. Recordings via the opened infundibular recess did not reveal any alterations of the spontaneous activity of the recorded neurons after light stimuli (GEORGE and MEISSL, 1987), a result refuting a photoreceptive role for the organ. Studies in the duck (KoRF et al., 1982) indicated that physiologically identified - presumed CSF-contacting neurons of the paraventricular nucleus were involved in osmoreception.

Finally, we want to emphasize the multiplicity of the CSF-contacting neurons: they differ in the structure of their intraventricular receptor terminals and their content of bioactive materials; they further belong to different nuclei of the periventricular grey (Fig. 16). Our immunocytochemical studies in progress are aimed at elucidating the chemical nature of the substances involved in both receptor and effector functions of various areas of the CSF-contacting neuronal system.

\section{REFERENCES}

Agardh, E., A. Bruun, B. Ehinger, P. Ekström, T. van VEEN and J. Y. WU: Gamma-aminobutyric acid and glutamine acid decarboxylase-immunoreactive neurons in the retina of different vertebrates. J. Comp. Neurol. 258: 622-630 (1987).

Aghajanian, G. K. and M. Gallager: Raphe origin of serotonergic nerves terminating in the cerebral ventricles. Brain Res. 88: 221-231 (1975).

Andersson, B.: Receptors subserving hunger and thirst. In: (ed. by) E. NEIL: Handbook of sensory physiology, Vol. 3/1, Enteroceptors. Springer, Berlin-Heidelberg, 1972 (p. 187-216). 
Chytil, F. and D. E. ONG: Intracellular vitamin Abinding protein. Ann Rev. Nutr. 7: 321-335 (1987).

CONRAD, D. H. and G. H. WirTz: Characterization of antibodies to vitamin A. Immunochemistry 10: 273-275 (1973).

Dale, N., A. Roberts, A. Ottersen and J. O. P. STORM-MATHISEN : The morphology and distribution of Kolmer-Agduhr cells, a class of cerebrospinal-fluidcontacting neurons revealed in the frog embryo spinal cord by GABA immunocytochemistry. Proc. Roy. Soc. Lond. Ser. B. 232: 193-203 (1987).

Doerr-SchotT, J., M. P. Dubois and Ch. Lichte: Immunohistochemical localization of substances reactive to antisera against $\alpha$ - and $\beta$-endorphin and met-enkephalin in the brain of Rana temporaria L. Cell Tiss. Res. 217: 79-92 (1981).

Ekström, P.: Distribution of choline acetyltransferaseimmunoreactive neurons in the brain of a Cyprinid teleost (Phoxinus phoxinus L.). J. Comp. Neurol. 256: 494515 (1987).

Ekström, P., L. Nyberg and T. van Veen: Ontogenetic development of serotoninergic neurons in the brain of a teleost, the three-spined stickle-back. An immunohistochemical analysis. Devel. Brain Res. 17: 209-224 (1985).

Fasolo, A., M. F. Franzoni, G. Gaudino and H. W. M. STEINBUSCH: The organization of serotonin-immunoreactive neuronal systems in the brain of the crested newt, Triturus cristatus carnifex Laur. Cell Tiss. Res. 243: 239-247 (1986).

Foster, R. G., H. W. Korf and J. J. Schalken: Immunocytochemical markers revealing retinal and pineal but not hypothalamic photoreceptor systems in the Japanese quail. Cell Tiss. Res. 248: 161-167 (1987).

Franzoni, M. F., M. G. Martinoli and J. Thibault: Tyrosine hydroxylase immunoreactive neurons in the hypothalamus of the crested newt. An electron microscopic study. Basic Appl. Histochem. 31: 63-72 (1987).

Geffen, L., T. Jessell, A. Cuello and L. L. Iversen: Release of dopamine from dendrites in rat substantia nigra. Nature (London) 260: 258-261 (1976).

Geffard, M., O. KaH, P. Chambolle, M. Le Moal and M. DelaAge: Premiere application immunocytochimique d'un anticorps antidopamine a l'etude du systeme nerveux central. C. R. Acad. Sci. Paris Ser. III. 295: 797802 (1982).

George, S. R. and H. MeissL: An attempt to record neuronal activity in the paraventricular organ of Rana esculenta by means of a direct access to the infundibular recess. Cell Tiss. Res. 250: 53-56 (1987).

Grillner, S., A. McClellan and K. SigvardT: Mechanosensitive neurons of the spinal cord of the lamprey. Brain Res. 235: 169-173 (1982).

Grillner, S., T. Williams and P. A. Lagerback: The edge cell, a possible intraspinal mechanoreceptor. Science 223: 500-503 (1984).

Hellon, R. F.: Central thermoreceptors and thermoregulation. In: (ed. by) E. NEIL: Handbook of sensory physiology, Vol. 3/1, Enteroceptors. Springer, Berlin-
Heidelberg, 1972 (p. 161-186).

Inenaga, K., T. Osaka and H. Yamashita: Thermosensitivity of neurons in the paraventricular nucleus of the rat slice preparation. Brain Res. 424: 126-132 (1987).

Jewell, P. A. and E. B. Verney: An experimental attempt to determine the site of the neurohypophysial osmoreceptors in the dog. Phil. Trans. B 240: 197-234 (1957).

Kaduri, A. J., R. Magoul, L. Lescaudron, G. Campis TRON and A. CAlas: Immunocytochemical approach of GABA-ergic innervation of the mouse spinal cord using antibodies to GABA. J. Hirnforsch. 28: 349-335 (1987).

Korf, H. W., Chr. Simon-Oppermann and E. Simon: Afferent connections of physiologically identified neuronal complexes in the paraventricular nucleus of conscious Pekin ducks envolved in regulation of salt- and water-balance. Cell Tiss. Res. 226: 275-300 (1982).

LARSON, B. A. and H. A. BERn: The urophysis and osmoregulation. In: Vertebrate Endocrinology: Fundamentals and biomedical implications, Vol. 2. Academic Press, New York, 1987 (p. 143-156).

LEONHARDT, H.: Ependym und circumventriculare Organe. In: (ed. by) A. OKSCHE and L. Vollrath: Handbuch der mikroskopischen Anatomie des Menschen, Vol. 4/10, Springer, Berlin-Heidelberg, 1980 (p. 177-666).

Magoul, R., B. Onteniente, M. GefFard and A. Calas: Anatomical distribution and ultrastructural organization of the GABaergic system in the rat spinal cord. An immunocytochemical study using anti-GABA antibodies. Neuroscience 20: 1001-1009 (1987).

Matsudra, T., Y. Takeuchi, M. Kojima, S. Ueda, H. Yamada, Y. Noyo, K. UshiJima and Y. SANo: Immunohistochemical studies of the serotonergic supraependymal plexus in the mammalian ventricular system, with special reference to the characteristic reticular ramification. Acta Anat. 123: 207-219 (1985).

Nagatsu, I., N. Karasawa, Y. Kawakami and M. Yoshida: Studies on monoamine-containing neurons by immunoenzyme-histochemistry and immunohistochemistry with special reference to goldfish brain. Acta Histochem. Cytochem. 17: 151-160 (1984).

NaIK, D. R., M. SAR and W. E. STUMPF: Immunohistochemical localization of enkephalin in the central nervous system and pituitary of the lizard, Anolis carolinensis. J. Comp. Neurol. 198: 583-602 (1981).

Richards, J. G. and J. P. Tranzer: Ultrastructural evidence for the localization of an indolealkylamine in supraependymal nerves from combined cytochemistry and pharmacology. Experientia 30: 287-289 (1974).

Rodriguez, E. M., Z. Baigarria, A. Rodriguez and D. CroccA: Evidence for the periventricular localization of the hypothalamic osmoreceptors. Acta Physiol. Latinamer. 24: 414-417 (1974).

Sano, Y., S. Ueda, H. Yamada, Y. Takeuchi, M. Goto and M. KAWATA: Immunohistochemical demonstration of serotonin-containing CSF-contacting neurons in the submammalian paraventricular organ. Histochemistry 77: 423-430 (1983). 
SCHARRER, E.: Die Lichtempfindlichkeit blinder Elritzen. Z. Vergl. Physiol. 7: 1-38 (1928).

Schroeder, D. M.: An ultrastructural study of the marginal nucleus, the intrinsic mechanoreceptor of the snake's spinal cord. Somatosensory Res. 4: 127-140 (1986).

Silver, R., P. Witkovsky, R. Horvath, V. Alones, C. J. Barnstable and M. N. Lehman: Coexpression of opsin and VIP-like immunoreactivity in CSF-contacting neurons of the avian brain. Cell Tiss. Res. 253: 189-198 (1988).

Tramu, G., A. Pillez and J. Leonardelli: Serotonin axons of the ependyma and circumventricular organs in the forebrain of the guinea pig. An immunohistochemical study. Cell Tiss. Res. 228: 297-311 (1983).

VERNEY, E. B.: The antidiuretic hormone and the factors which determine its release. Proc. Roy. Soc. Lond. Ser. B. 135: 25-105 (1947).

Vigh, B. and I. Vigh-Teichmann: Structure of the medullo-spinal liquor contacting neuronal system. Acta Biol. Acad. Sci. Hung. 22: 227-243 (1971).

: Comparative ultrastructure of the cerebrospinal fluid-contacting neurons. Int. Rev. Cytol. 35: 189-251 (1973).

- : Light and electron microscopic demonstration of immunoreactive opsin in the pinealocytes of various vertebrates. Cell Tiss. Res. 221: 451-463 (1981).

-: Three types of photoreceptors in the pineal and frontal organs of frogs: Ultrastructure and opsin immunoreaction. Arch. Histol. Jap. 49: 391-414 (1986).

- The pineal organ: A component of the CSF-contacting neuronal system. Wiss. Z. KarlMarx-Univ. Math.-Nat. Ser. 36: 30-34 (1987).

- Comparative neurohistology and immunocytochemistry of the pineal complex with special reference to CSF-contacting neuronal structures. Pineal Res. Rev. 6: 1-65 (1988a).

- - Pineal CSF-contacting neurons and nerve cells disposing of $9+0$ cilia are secondary neurons of the pineal photosensory pathway. Verh. Anat. Ges. 82: (1988b, in press).

- : The pinealocyte forming receptor and effector endings: Immunoelectron microscopy and calcium histochemistry. Arch. Histol. Cytol. 52 Suppl.: 433-440 (1989).

Vigh, B., I. Teichmann and B. Aros: Das Paraventricularorgan und das Liquorkontakt-Neuronensystem. Anat. Anz. Suppl. 125: 683-688 (1969).

Vigh, B., I. Vigh-Teichmann and B. Aros: Intraependymal cerebrospinal fluid-contacting neurons and axon terminals on the external surface in the filum terminale of the carp. Cell Tiss. Res. 148: 359-370 (1974).

- - Special dendritic and axonal endings formed by the cerebrospinal fluid contacting neurons of the spinal cord. Cell Tiss. Res. 183: 541-552 (1977).
Vigh, B., I. Vigh-Teichmann, B. Aros, K. Sikora, L. Jennes, P. Simonsberger and H. AdAM : Comparative electron microscopy of medullo-spinal cerebrospinal fluid contacting neurons. Mikroskopie 35: 330-353 (1979).

Vigh, B., I. Vigh-Teichmann, M. J. Manzano e Silva and A. N. VAN DEN PoL: Cerebrospinal fluid-contacting neurons of the central canal and terminal ventricle in various vertebrates. Cell Tiss. Res. 231: 615-521 (1983a).

Vigh, B., I. Vigh-TeichmanN, P. Röhlich and A. OKSCHE: Cerebrospinal fluid-contacting neurons, sensory pinealocytes and Landolt's clubs of the retina as revealed by means of an electron-microscopic immunoreaction against opsin. Cell Tiss. Res. 233: 539-548 (1983b).

Vigh, B., G. H. WiRTz and I. Vigh-TeichmanN: Immunocytochemical demonstration of vitamin A in retina and pineal organ. Neuroscience Suppl. 22: S416 (1987).

Vigh-TeichmanN, I. and B. Vigh: The infundibular cerebrospinal-fluid contacting neurons. Adv. Anat. Embryol. Cell Biol. 50: 1-91 (1974).

- : A comparison of epithalamic, hypothalamic and spinal neurosecretory terminals. Acta Biol. Acad. Sci. Hung. 30: 1-39 (1979).

- : The system of cerebrospinal fluid contacting neurons. Arch. Histol. Jap. 46: 427-468 (1983).

: CSF-contacting neurons and pinealocytes. In: (ed. by) B. MEss, Cs. RuzsÁs, L. TimA and P. PÉveT: The pineal gland. Current state of pineal research. Akadémiai kiadó, Budapest, 1985 (p. 71-88).

-: The pinealocyte: Its ultrastructure and opsin immunocytochemistry. Adv. Pineal Res. 1: 31-40 (1986).

: Cerebrospinal fluid (CSF)-contacting dendrite terminals ("Landolt's clubs"?) in the pineal organ of Chimaera monstrosa. In: (ed. by) B. SCHARRER, H. W. KORF and H. G. HARTwIG: Functional morphology of neuroendocrine systems: evolutionary and environmental aspects. Springer, Berlin 1987 (p. 160).

Vigh-Teichmann, I., B. Vigh and B. Aros: CSF contacting axons and synapses in the lumen of the pineal organ. Z. Zellforsch. 144: 139-152 (1973).

— - Ciliated perikarya, "peptidergic" synapses and supraependymal structures in the guinea pig hypothalamus. Acta Biol. Acad Sci. Hung. 31: 373-394 (1980a).

Vigh-TeichmanN, I., P. Röhlich, B. Vigh and B. Aros: Comparison of the pineal complex, retina and cerebrospinal fluid-contacting neurons by immunocytochemical antirhodopsin reaction. Z. Mikrosk.-Anat. Forsch. 94: 623-640 (1980b).

Vigh-Teichmann, I., B. Vigh, B. Aros, M. Kausz, P. Simonsberger and A. N. VAN Den PoL: CSF contacting neuronal structures of the third ventricle of opossum, hedgehog and cat. Mikroskopie 38: 337-355 (1981). 
Vigh,-Teichmann, I., B. Vigh, I. Gery and T. van VEEN: Different types of pinealocytes as revealed by immunoelectron microscopy of anti-S-antigen and antiopsin binding sites in the pineal organ of toad, frog, hedgehog and bat. Exp. Biol. 15: 27-43 (1986).

Vigh-TeichmanN, I., B. Vigh and G. H. WirtZ: Vitamin A immunoreactivity of the retina and pineal complex in various vertebrates. Serono Symp. Ser. 44: 61-64 (1987).

Vigh-TeichmanN, I., B. Vigh, A. Szél, P. Röhlich and G. H. WiRTz: Immunocytochemical demonstration of vitamin A in the retina and pineal organ of the frog Rana esculenta. Histochemistry 88: 533-543 (1988).

Vigh-TeichmanN, I., B. Vigh and G. H. Wirtz: Immunoelectron microscopy of vitamin A and rhodopsin in the pineal organ and retina of the lamprey. Exp. Biol. (1989, in press).

Von Frisch, K.: Beiträge zur Physiologie der Pigmentzellen in der Fischhaut. Pflügers Arch Ges. Physiol. 138: 319-387 (1911).
WIRTZ, G. H. and S. S. WeSTFALL: Reactivity of vitamin A derivatives and analogues with vitamin A antibodies. J. Lipid Res. 22: 869-871 (1981).

Yoshida, M., I. Nagatsu, Y. Kondo, N. Karasawa, T. Ohno, M. Spatz and T. Nagatsu: Two cell types in monoamine-containing "liquor contacting" neuron system of the frog brain. Experientia 38: 1097-1099 (1982).

YUI, R.: Immunohistochemical studies on peptide neurons in the hypothalamus of the bullfrog Rana catesbeiana. Gen. Comp. Endocrinol. 49: 195-209 (1983).

Dr. I. Vigh-TeichmanN

Dr. B. VIGH

2nd Department of Anatomy

Semmelweis OTE, Tüzoltó utca 58

H-1094 Budapest, Hungary 